\title{
Migração Espontânea Tardia da Ponta de um Catéter Venoso Central
}

\section{Late Spontaneous Migration of the Tip of a Central Venous Catheter}

Homem de 74 anos, com antecedentes pessoais de hipertensão arterial, dislipidemia, insuficiência cardíaca congestiva e hiperplasia benigna prostática, seguido em consulta de oncologia por adenocarcinoma da transição reto-sigmoideia (pT3N2MOG2R0) submetido em em Janeiro de 2015 a cirurgia de resseção anterior do reto. Colocação bem conseguida de catéter venoso central (CVC) em Abril de 2015 após tentativa falhada 15 dias antes. Realizou 8 ciclos de quimioterapia FOLFOX adjuvante até ao final do ano de 2015 pelo CVC tendo mantido vigilância clínica desde então. Na última consulta de oncologia no raio-x torácico de controlo verificou-se CVC partido com migração da sua porção distal (Figura 1). Clinicamente o paciente referiu apenas episódio de síncope com hipotensão 3 dias antes tendo-se assintomático desde então. Uma angio-tomografia torácica confirmou o achado com a presença da parte proximal do catéter infra-adjacente aos planos musculares na região peitoral e a parte migrada do cateter na artéria segmentar basal posterior do lobo inferior direito (Figura 2). Em reunião de grupo multidisciplinar com cirurgia-cardiotorácica e devido ao perfil risco-benefício adverso, decidiu-se pela não remoção da ponta migrada.

Neste caso clínico descrevemos a migração tardia da ponta de um CVC. Este fenómeno não é incomum e foram já descritos vários destinos anatómicos para estas migrações como a veia braquiocefálica oposta, veia jugular ou veia cava ${ }^{1,2}$. A incidência destas migrações espontâneas foi estimada em 0.9-1.8\%, sendo que o mecanismo exato permanece obscuro. Algumas hipóteses incluem variações extremas da pressão intratorácica por tosse, estornutos ou levantamento de pesos por exemplo ${ }^{3}$.

\section{Bibliografía}

1. DiGiacomo JC, Tarlian HS. Spontaneous migration of long-term indwelling venous catheters. JPEN J Parenter Enteral Nutr. 1991 Sep-0ct;15(5):574-7.

2. Prabaharan B, Thomas S. Spontaneous migration of central venous catheter tip following extubation. Saudi Journal of Anaesthesia. 2014;8(1):131-133. doi:10.4103/1658354X.125975.

3. Miller JA, Singireddy S, Maldjian P, Baker SR. A reevaluation of the radiographically detectable complications of percutaneous venous access lines inserted by four subcutaneous approaches. Am Surg.1999;65:125-30

4. Ko SY, Park SC, Hwang JK, Kim SD. Spontaneous fracture and migration of catheter of a totally implantable venous access port via internal jugular vein--a case report. J Cardiothorac Surg. 2016 Apr 11;11:50

\section{Diagnóstico: Migração Espontânea Tardia da Ponta de um Catéter Venoso Central} João Miguel Carvas ${ }^{1}$, Catarina Rocha²

${ }^{1}$ Interno de Formação Especifica em Cirurgia Geral do $1^{\circ}$ ano, Serviço de Cirurgia Geral, ULSNE. 2. Médico Assistente, Serviço de Cirurgia Geral, ULSNE - Unidade Local de Saúde do Nordeste Transmontano

Correspondencia: jmcarvas@gmail.com

Como citar este artículo: Carvas JM, Rocha C

Migração Espontânea Tardia da Ponta de um Catéter Venoso Central. Galicia Clin 2017; 78 (1): XX-XX Recibido: 23/08/16; Aceptado: 14/10/16
Figura 1. Raio-X torácico a mostrar a ponta do cateter migrado (setas brancas) no pulmão direito.

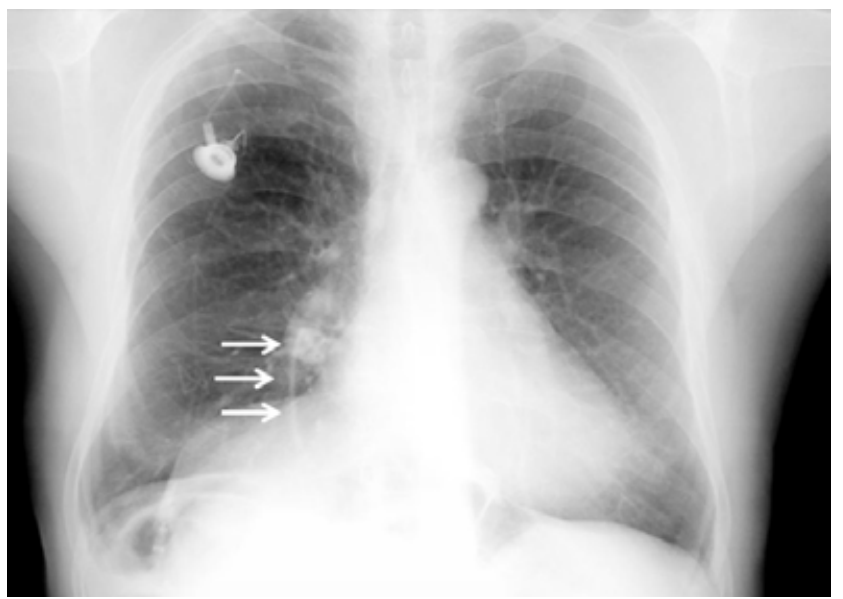

Figura 2. Tomografia Computorizada torácica a mostrar a ponta do cateter migrado (setas brancas) na artéria segmentar basal e segmentar basal posterior do lobo inferior direito.

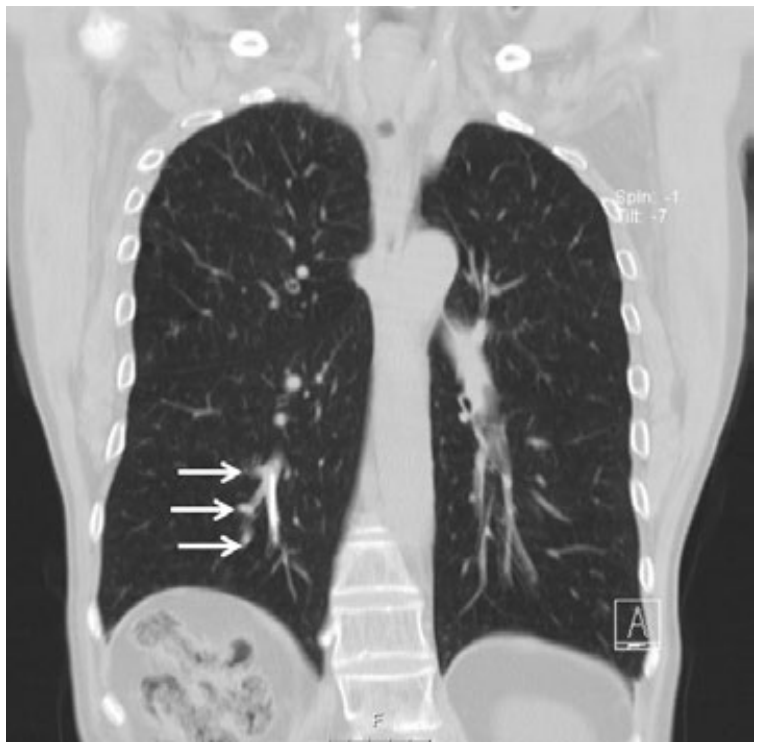

